\title{
Reinforced Roadbed Deformation Characteristics Under Moving Wheel Loads
}

\author{
Yoshitsugu MOMOYA, Dr. Eng. \\ Researcher, \\ Etsuo SEKINE, Dr. Eng. \\ Track Structures and Geotechnology G., Track Technology Div.
}

\begin{abstract}
For the purposes of an introductory study into performance-based design methods for asphalt concrete-reinforced roadbeds, the deformation characteristics of roadbeds were investigated by means of scale model tests. A fixed-point loading test applying repeated loads to the same point of a rail, which is the conventional loading test method, has an inevitable problem in that the settlement of the sleeper just beneath the loading point becomes greater than that of adjacent sleepers. To avoid this problem, a moving-wheel loading method was adopted for this study. This paper discusses the differences between the deformation characteristics of reinforced roadbeds under fixed-point and moving-wheel loads.
\end{abstract}

Keywords: asphalt concrete, reinforced roadbed, moving-wheel loading, scale model test, Finite Element Method (FEM) analysis

\section{Introduction}

The reinforced roadbed, a cross section of which is shown in Fig.1, consists of asphalt concrete layer and crushed concrete layer. Its primary function is to support ballasted tracks firmly and reduce the formation of track irregularities. Furthermore, reinforced roadbeds reduce train loads that adversely affect on the subgrade deformation. Therefore, reinforced roadbeds are widely used for ballasted tracks in Japan. In the current design standard of reinforced roadbeds, the depth of which is determined to satisfy the specified deformation limit in elastic half-space model analysis. However, the current design standard does not take into account any flexible design parameters that consider either train loads or the frequency of train passing. The design methods for structures are now at a transition stage to a performance-based design method to reduce life cycle costs. Therefore it is necessary to develop new design method for reinforced roadbeds. In the case of asphalt concrete paving for roads, performance-based design method is applied, in which the service life is governed by fatigue criteria of the asphalt concrete layer. Hence, by introducing fatigue criteria of the asphalt concrete into the design of reinforced roadbed, performance-based design of reinforced roadbed becomes possible. For the basic study to introduce fatigue criteria of asphalt concrete, deformation characteristic of reinforced roadbed was thoroughly investigated in this study.

The critical question here is the method needed to obtain correct deformation characteristic of reinforced roadbed. In the fatigue criteria of asphalt concrete, resilient tensile strain is important parameter. In the design of paved roads, the strain of asphalt concrete layer is obtained by multi-layer elastic analysis. However, railway roadbeds are subjected to the loads of complex track structures, which are composed of rails, sleepers and ballast. To obtain the exact strain of asphalt concrete in reinforced roadbed, which cannot be obtained by multilayer elastic analysis, it is necessary to use an analysis method that can model the exact shape of the track structure such as three-dimensional FEM. Hence, FEM analysis was introduced into this study, the results being compared with those of scale model tests to confirm its accuracy.

To investigate the deformation characteristics of railway track structures, fixed-point loading tests have frequently been conducted by applying a repeated load to the same point of a rail. Figure 2 shows a concept diagram of the effects of the two loading methods. In fixedpoint loading tests, there is an inevitable problem in that the settlement of the sleeper beneath the loading point becomes greater than that of adjacent sleepers. As a result, maximum load applied to the sleeper beneath the loading point gradually decreases with repeated loading. Therefore, fixed point loading cannot evaluate elastic deformation characteristic of reinforced roadbed properly. To solve this problem, a moving-wheel loading method was developed to move a wheel on the rail at a constant load. With this loading set-up, the maximum load applied to each sleeper changes little since each sleeper and the reinforced roadbed settle uniformly, enabling the evaluation of elastic deformation of the reinforced roadbed.

On the other hand, the continuous rotation of the direction of principal stress has long been thought to have an important effect on the residual deformation under moving-wheel loading. Nevertheless, a thorough investigation had as yet not been conducted on the difference

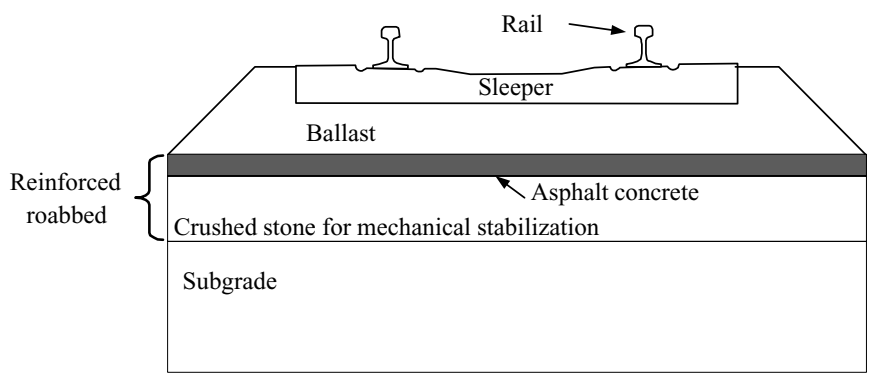

Fig. 1 Cross section of reinforced roadbed 


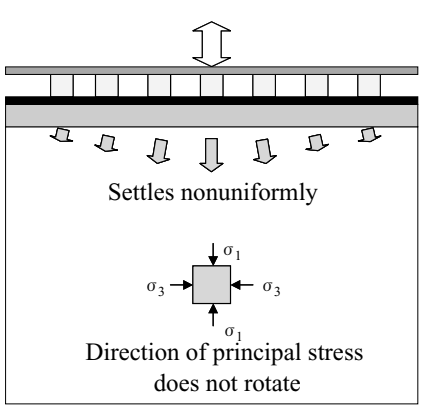

(a) Fixed-point loading

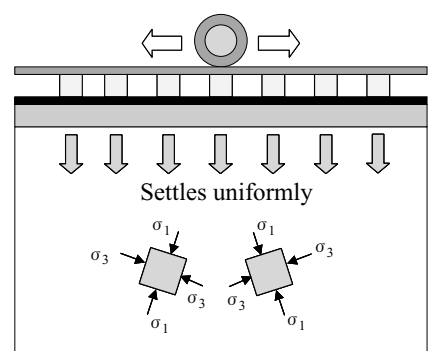

Direction of principal stress rotates

(b) Moving-wheel loading
Fig. 2 Effect of loading method

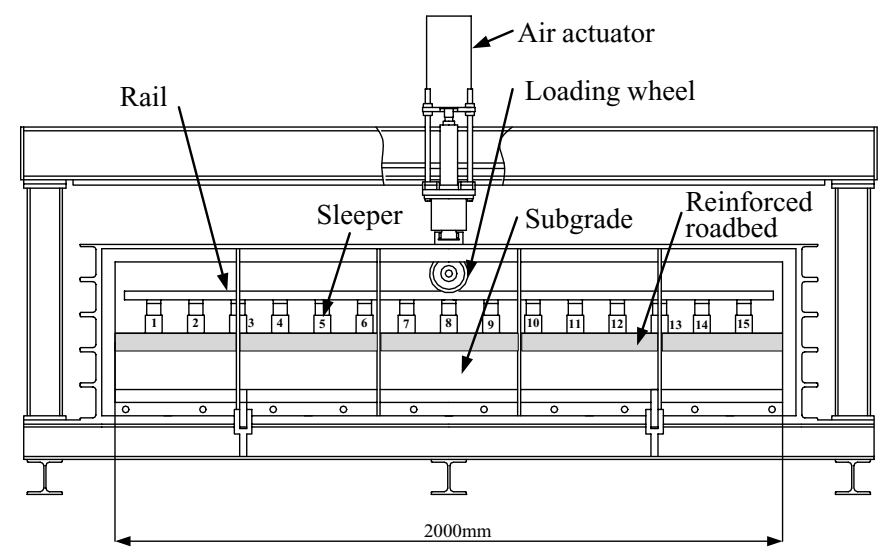

Fig. 3 Test apparatus for moving-wheel loading test

between fixed-point and moving-wheel loading. In this study, deformation characteristics for both were investigated.

\section{Moving-wheel loading test method}

Figure 3 shows the test apparatus for a moving wheel loading test, in which a loading wheel reciprocates with a given vertical load at a speed of $60 \mathrm{~cm} / \mathrm{min}$ repeatedly between the two rail ends. The scale of the model, which was composed of two rails, fifteen sleepers, a reinforced roadbed and subgrade, was $1 / 5$. Figure 4 shows the scale model in detail. A real reinforced roadbed composed of an asphalt concrete top layer and a crushed stone bottom layer. In this scale model, the reinforced roadbed was made of CA mortar for the asphalt concrete layer and bituminous stabilized crushed stone for the crushed stone layer. The subgrade was made of Toyoura sand, which is typically used for model tests in geotechnical research. Three different reinforced roadbed thicknesses of 4, 7 and $10 \mathrm{~cm}$ were adopted for the scale model tests. A control with no roadbed was also carried out. The ballast layer was not modeled in this study to avoid scattering of test results.

Figure 5 shows the loading pattern for the movingwheel loading tests. At both rail ends, the applied wheel load was decreased to $1 / 5$ to settle the sleepers uniformly. Otherwise, the settlement of the end sleepers would have become greater than that of the sleepers at the center. The maximum wheel load was $1.5 \mathrm{kN}$ for the first 100 loadings, which was increased to $3 \mathrm{kN}$ thereafter. Dur- ing the $3 \mathrm{kN}$ moving-wheel loading test, fixed-point loading test was conducted. In the fixed-point loading test, the loading wheel was fixed above sleeper No. 8 to apply repeated load at the same point of the rail.

In these tests, measurements were taken for the vertical load on the sleepers, the vertical and shear stresses at the bottom of the subgrade, the strain at the bottom of the CA mortar, and for sleeper displacement. The wheel load and position were simultaneously monitored. These values were recorded and stored in a computer at intervals of 0.1 seconds.

To observe the deformation in the subgrade, image processing was adopted. A schematic view of image processing method in this test is shown in Fig. 6. Black circular markers, $1.5 \mathrm{~mm}$ in diameter, were arranged in a 1 $\mathrm{cm}$-interval grid pattern on the latex membrane at the inside of transparent acrylic sidewall of the soil container. The movement of the markers was shot with a digital camera and the marker coordinates obtained from those pictures by using image processing software in computer. The strain of quadrangles element that were composed of four markers were obtained by the coordinates of those

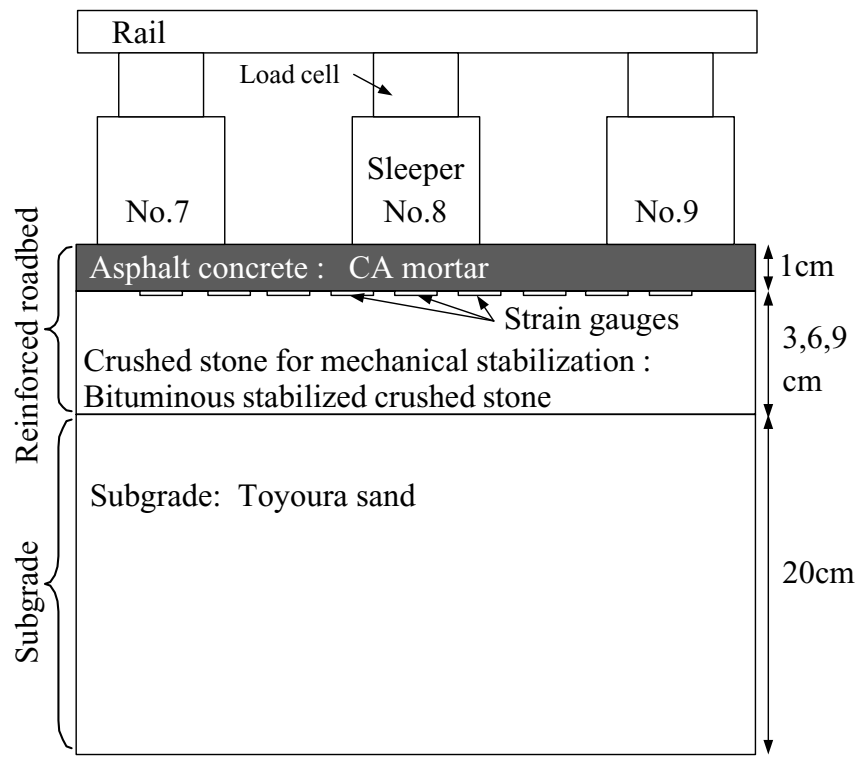

Fig. 4 Details of scale model

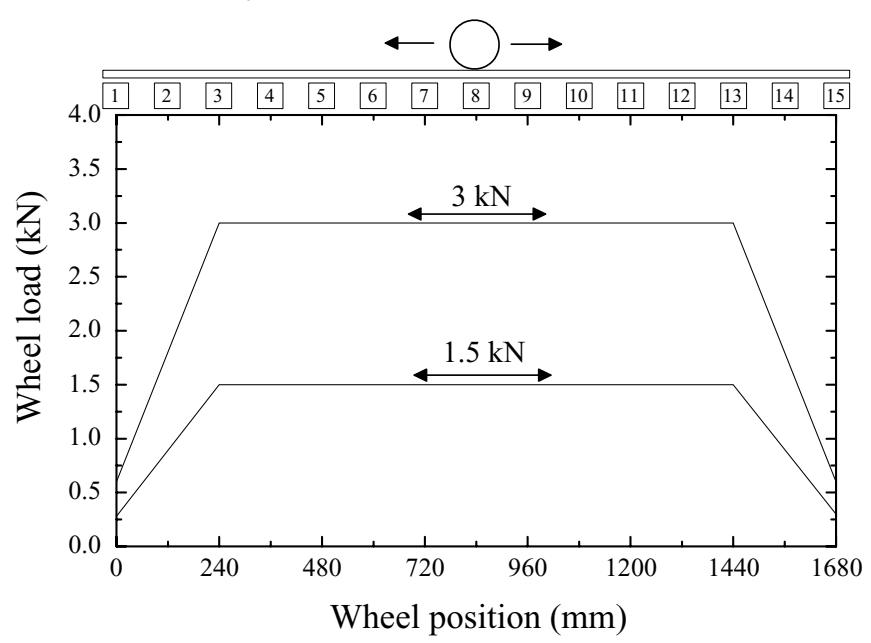

Fig. 5 Loading pattern for moving-wheel loading test 


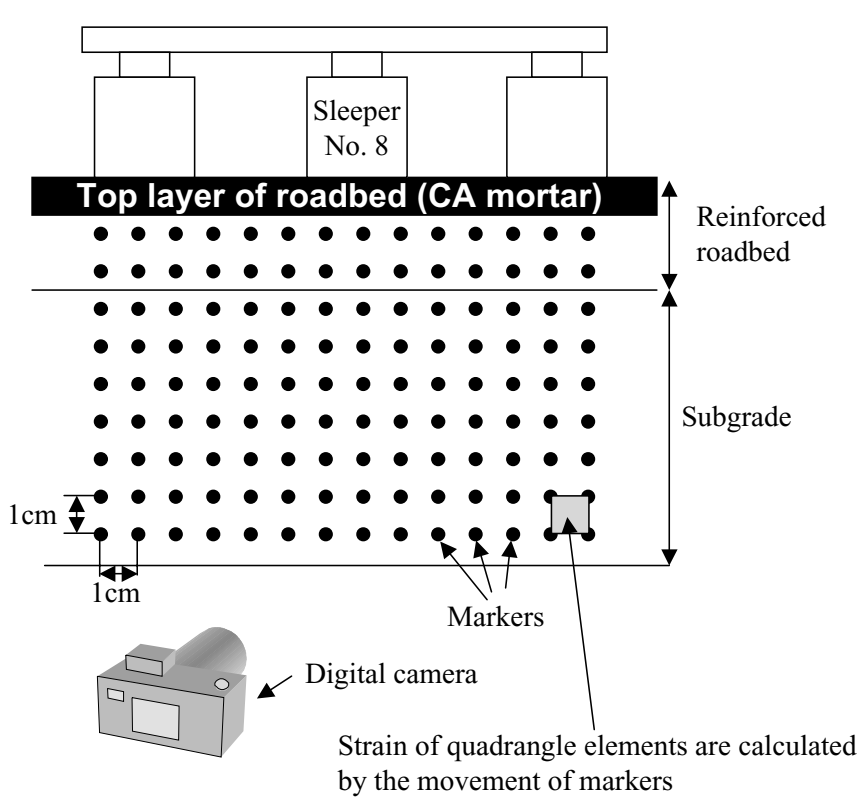

Fig. 6 Schematic view of image processing system

markers. By calculating strains of all elements, the strain distribution in the subgrade was obtained.

\section{FEM model}

A linear elastic FEM analysis was carried out to simulate the elastic deformation characteristics of the scale model. Figure 7 shows a three-dimensional analysis model by Nastran. The rail was modeled by beam elements, sleepers, reinforced roadbed and subgrade by solid

Table 1 Parameters for FEM analysis

\begin{tabular}{|c|c|c|c|}
\hline & $\begin{array}{c}\text { Young's } \\
\text { Modulus } \\
\mathrm{E}\left(\mathrm{MN} / \mathrm{m}^{2}\right)\end{array}$ & $\begin{array}{c}\text { Poisson's } \\
\text { Ratio } v\end{array}$ & $\begin{array}{c}\text { Type of } \\
\text { Element }\end{array}$ \\
\hline Rail & 210000 & 0.3 & Beam \\
\hline Sleeper & 210000 & 0.3 & Solid \\
\hline $\begin{array}{c}\text { Top layer of reinforced roadbed } \\
\text { (CA mortar) }\end{array}$ & 3500 & 0.3 & Solid \\
\hline $\begin{array}{c}\text { Bottom layer of reinforced roadbed } \\
\text { (Bituminous stabilized crushed stone) }\end{array}$ & 1000 & 0.3 & Solid \\
\hline $\begin{array}{c}\text { Subgrade } \\
\text { (Toyoura sand) }\end{array}$ & 50 & 0.3 & Solid \\
\hline
\end{tabular}

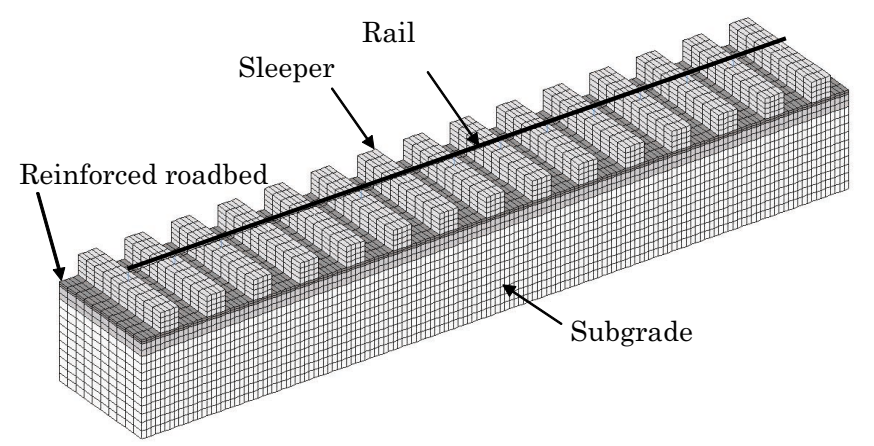

Fig. 7 FEM model elements. The Young's modulus of the reinforced roadbed was determined from the result of an unconfined compression test and that of the subgrade was from the result of a triaxial test. Table 1 shows the FEM analysis parameters.

\section{Effect of loading method}

Figure 8 shows the load-displacement relationship of sleeper No. 8 in the cases with and without a $4 \mathrm{~cm}$-thick reinforced roadbed. At the beginning of the test, wheel load was gradually increased to constant value of $1.5 \mathrm{kN}$. Thereafter, moving wheel loading was conducted with constant wheel load. The maximum vertical load applied to the sleeper slightly increased with repeated loading, even when the wheel load was constant, reaching a constant value. This was due to the increase in the stiffness of the reinforced roadbed and subgrade. The increase in the stiffness made the reaction force from the roadbed greater, making the load on the sleeper greater too. In fixed-point loading, by contrast, the maximum vertical load applied to the sleeper slightly decreased with repeated loading. Simultaneously, the increment of displacement in fixedpoint loading became less than that in moving-wheel loading.

Figure 9 compares the vertical loads applied to sleepers in both moving-wheel and fixed-point loading tests in the case without reinforced roadbed. In moving-wheel loading, each sleeper is loaded in the same way. Thus, supporting condition of each sleeper does not change each other. In fixed-point loading, by contrast, only the sleeper beneath the wheel was applied with the maximum load. For this reason, the settlement of the sleeper beneath the loading wheel became greater than that of adjacent sleepers, however the magnitude of the settlement was smaller than that of moving-wheel loading. This difference causes significant effect on the deformation characteristics in moving-wheel loading and fixed-point loading.

As mentioned above, moving-wheel and fixed-point loading brought about quite different deformation characteristics on the roadbed. This difference shows the importance of the loading method in repeated loading tests. The question that arises here is why the displacement in fixedpoint loading becomes much less than that of moving wheel loading. One of the conceivable reasons is the rotation of the direction of the principal stress in the roadbed and subgrade. As Wong \& $\operatorname{Arthur}^{1)}$ (1984) and Towhata et al. ${ }^{2)}$ (1994) showed, the rotation of principal stress has an important effect on soil deformation, which has an anisotropic property. Figure 10 shows the direction of principal stress in this scale model, which was obtained by FEM. It is generally said that a rotation of principal stress of more than 30 degrees has a considerable effect on residual deformation. However, the amount of rotation of principal stress in this test was not significant. Although the rotation of principal stress may have a certain effect on the deformation of subgrade, there could be another reason for the above phenomenon.

A possible second reason is the decrease in the maximum load applied to the sleeper under fixed-point loading. In this test, the load applied on the sleeper decreased 


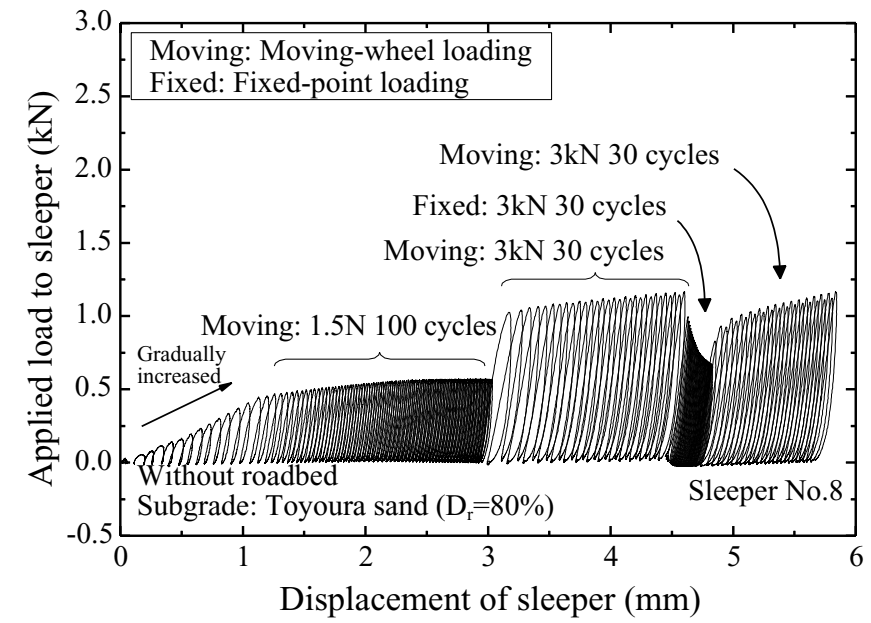

(a) Case without roadbed

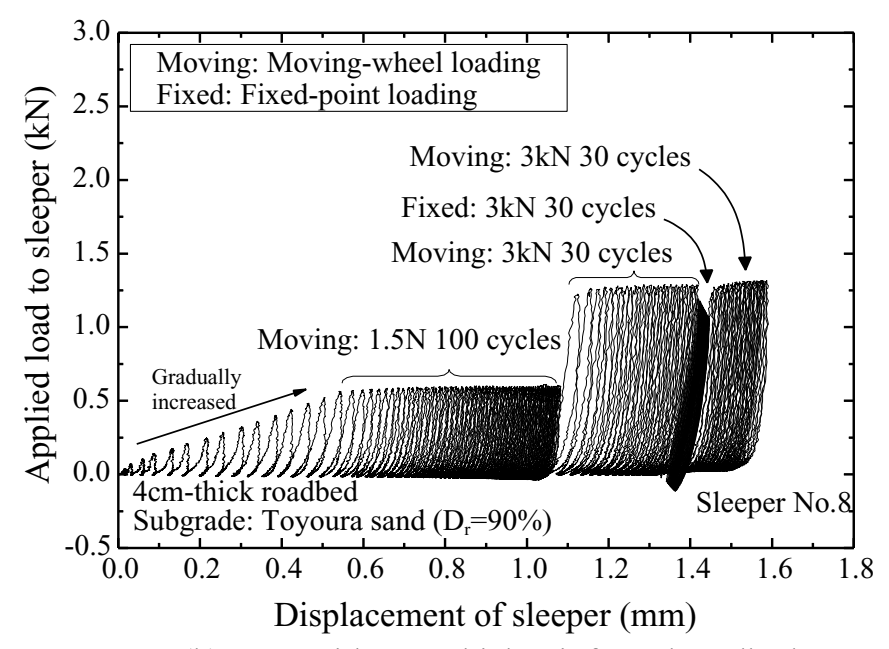

(b) Case with $4 \mathrm{~cm}$-thick reinforced roadbed

Fig. 8 Load-displacement relationship
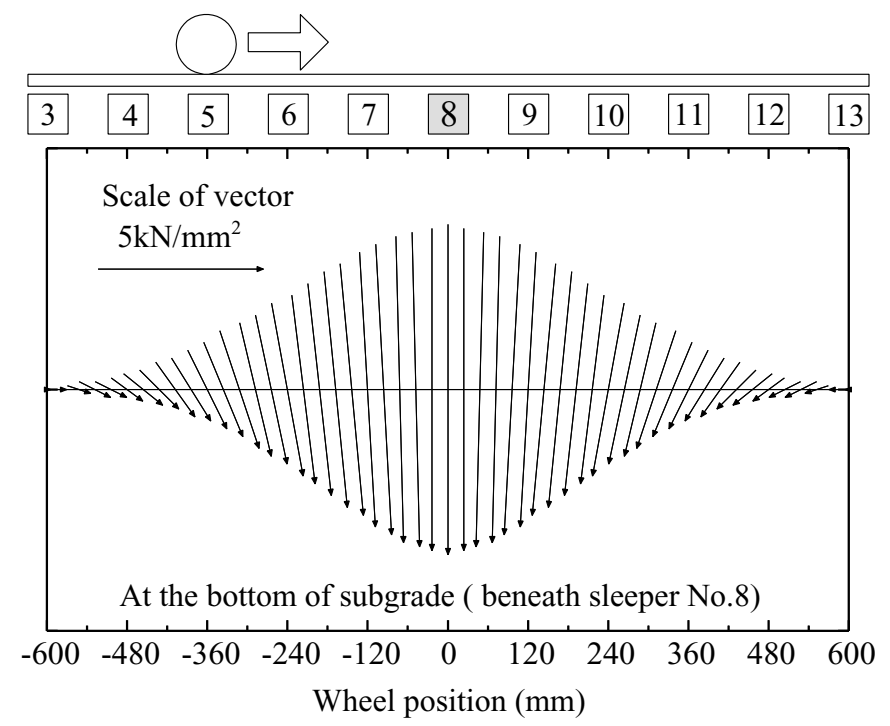

Fig. 10 Direction of principal stress

gradually with repeated loading, whereas that in movingwheel loading was slightly increased. Figure 11 shows the effect of load variation on a single-sleeper loading test,

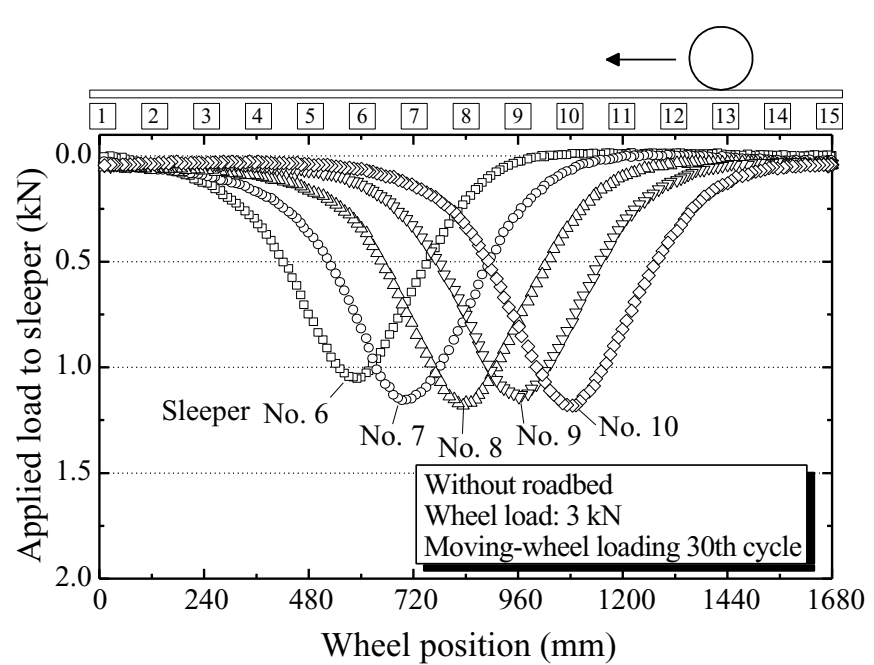

(a) Moving-wheel loading

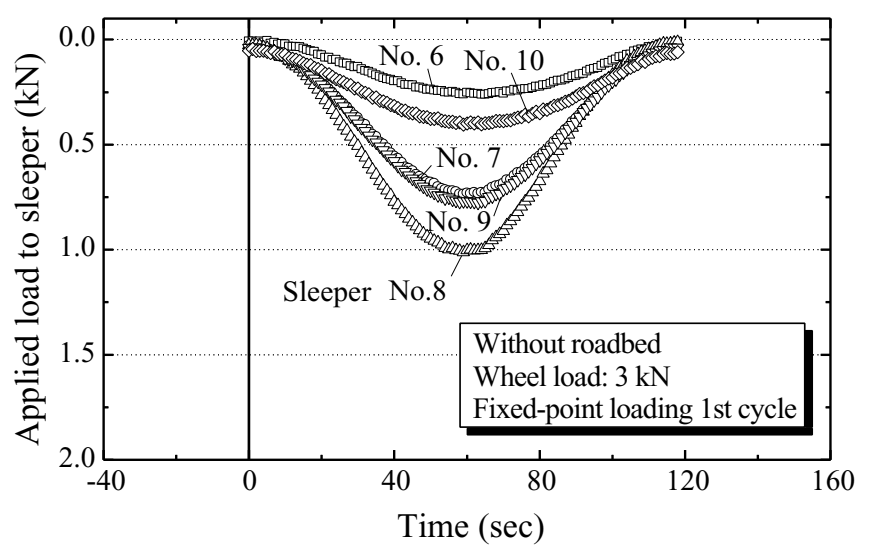

(b) Fixed-point loading

Fig. 9 Loads applied to sleepers

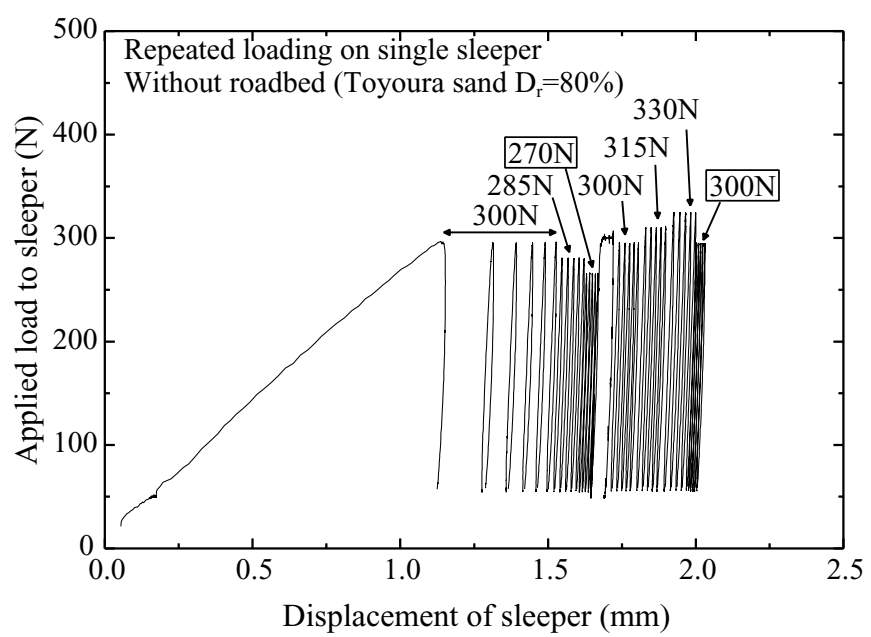

Fig. 11 Effect of applied load to sleeper

where application of each load was repeated 50 times. When the maximum load decreased from $300 \mathrm{~N}$ to $270 \mathrm{~N}$ or from $330 \mathrm{~N}$ to $300 \mathrm{~N}$, the increment of displacement significantly decreased, even when the maximum load only decreased by $10 \%$. This result shows that a slight decrease 
in maximum load has a significant effect on the displacement of the sleeper. Therefore, it seems reasonable to conclude that the decrease of sleeper load in fixed-point loading is a major factor in the differences of sleeper displacements. As has been noted, it has become clear that the moving-wheel loading method is necessary to evaluate the proper deformation characteristics of railway roadbeds.

\section{Function of reinforced roadbed}

An important function of a reinforced roadbed is to reduce the stress on the subgrade. Figure 12 shows the vertical loads applied to sleeper No. 8 by wheel movements in the cases with and without the $4 \mathrm{~cm}$-thick reinforced roadbed. When the loading wheel reached sleeper No. 5, the load applied to sleeper No. 8 started to increase. The load reached a peak when the wheel passed directly over sleeper No. 8. Then, the load decreased to almost zero at sleeper No. 11 . In the case with a $4 \mathrm{~cm}$-thick reinforced roadbed, the maximum load on sleeper No. 8 was larger than in the case without a roadbed. Due to the

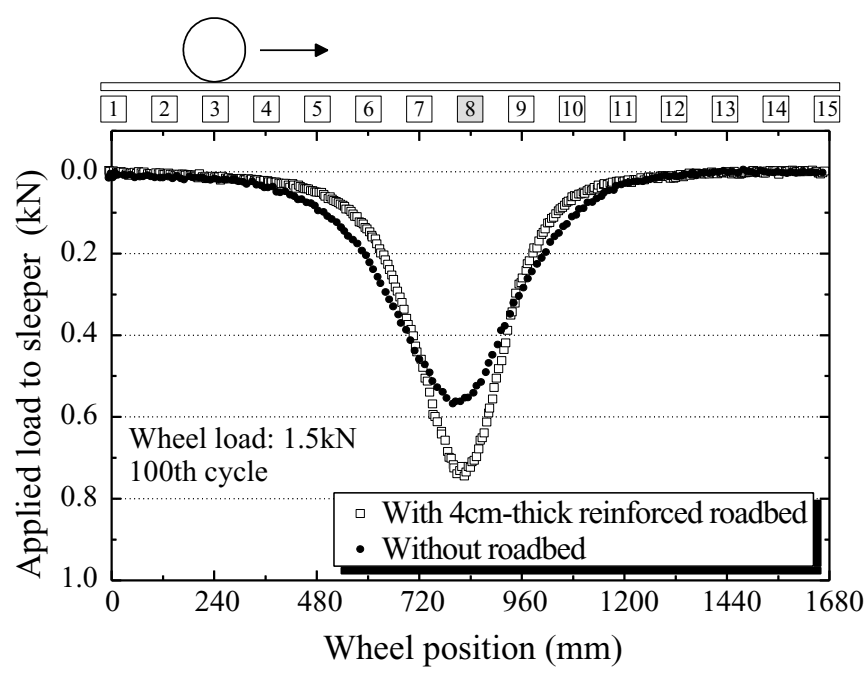

Fig. 12 Applied load to sleeper No. 8

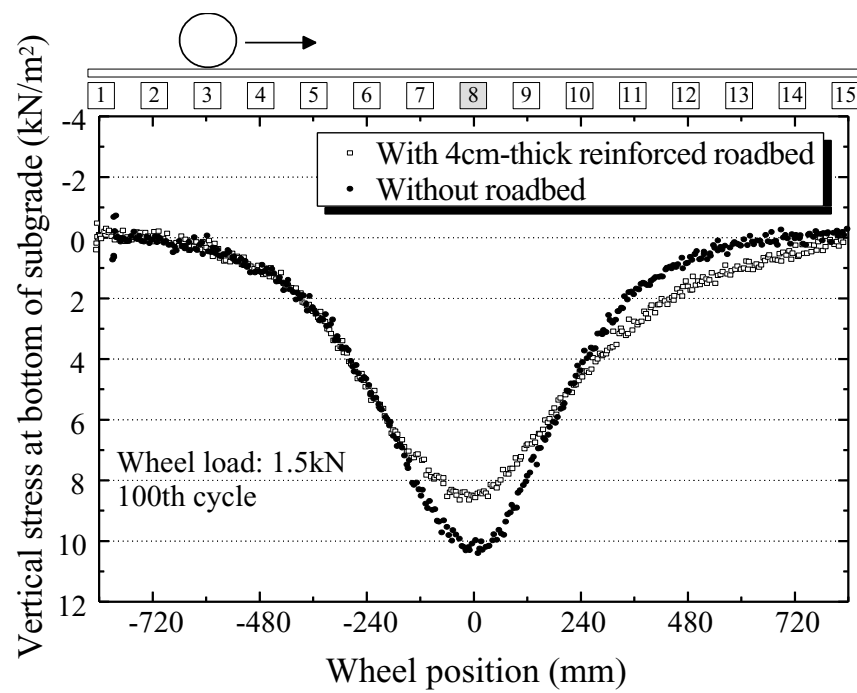

Fig. 13 Vertical stress at the bottom of subgrade

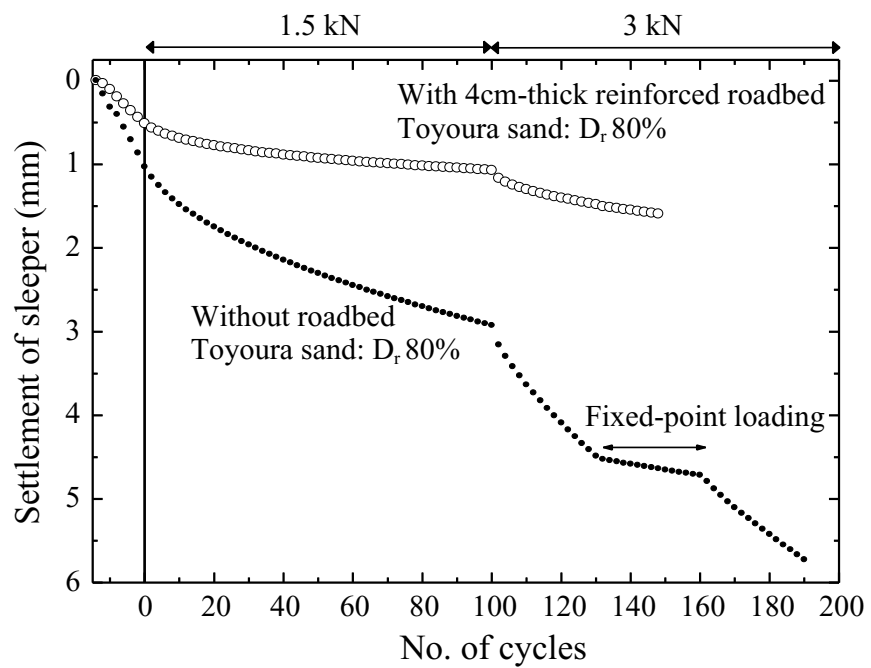

Fig. 14 Residual settlement of sleeper

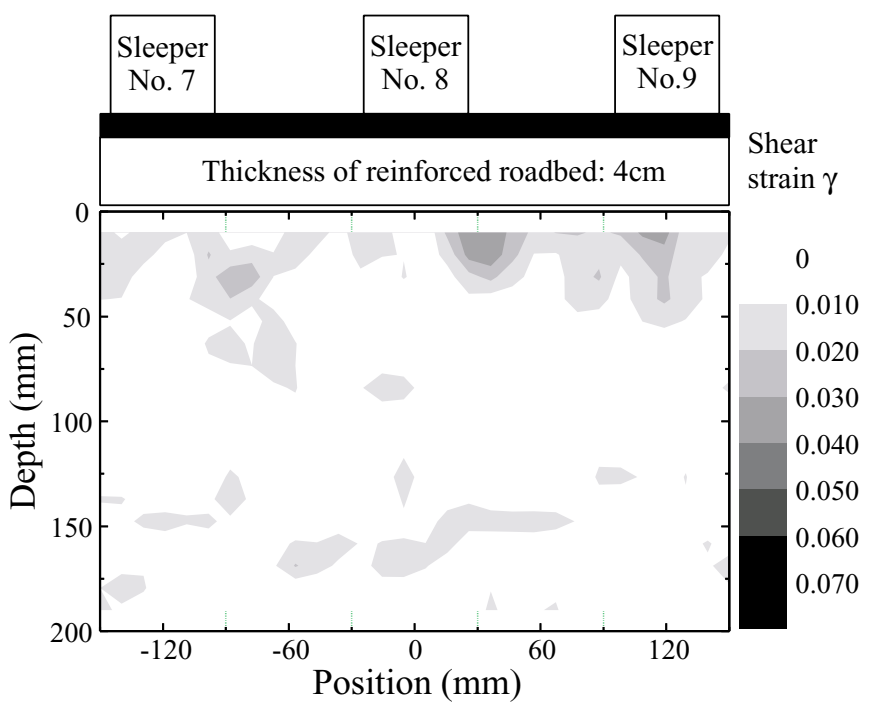

(a) $4 \mathrm{~cm}$-thick reinforced roadbed

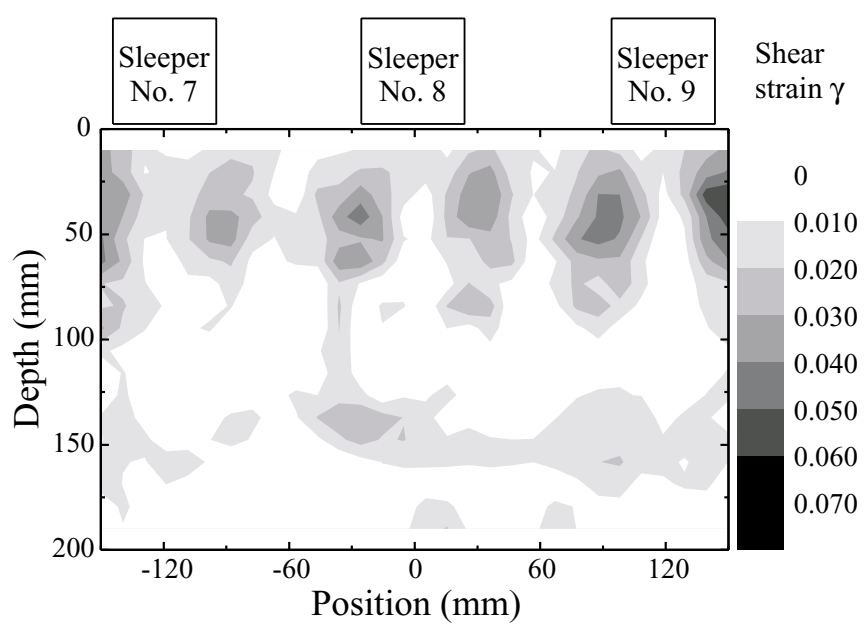

(b) Without roadbed

Fig. 15 Shear strain distribution in subgrade

stiffness of the reinforced roadbed, the reaction force to the sleeper becomes greater than in the case without a roadbed. However, Fig. 13 shows that the vertical stress 
at the bottom of the subgrade in the case without a roadbed becomes greater than in the case with a $4 \mathrm{~cm}$-thick reinforced roadbed. This result shows that the reinforced roadbed plays a role in decreasing the stresses applied to the subgrade.

Figure 14 shows the residual settlement of sleeper in the case with a $4 \mathrm{~cm}$-thick reinforced roadbed and in the case without a roadbed. The residual settlement was greater in the case without a roadbed than in the case with a $4 \mathrm{~cm}$-thick reinforced roadbed. Figure 15 shows the shear strain distribution obtained by image processing in the scale model test. In the case without a roadbed, the shear strain concentrates beneath the edge of the sleeper. In contrast, in the case with a $4 \mathrm{~cm}$-thick reinforced roadbed, shear strain did not concentrate beneath the sleepers but was distributed uniformly.

Since the strain beneath the sleepers is minimal, the settlement of the sleeper was less in the case with the reinforced roadbed. From these results, it was shown that the reinforced roadbed has an important function to reduce subgrade deformation.

\section{Elastic deformation characteristic}

Figure 16 shows the loads applied to each sleeper in the case of a $4 \mathrm{~cm}$-thick reinforced roadbed when the loading wheel is just over sleeper No. 8. The loads applied to sleepers were obtained from the scale model test and FEM. In this model, approximately $55 \%$ of the wheel load was sustained by the sleeper just under the loading wheel, and $20 \%$ by the sleeper adjacent to it. In an actual ballasted track, the sleeper under the wheel sustains about $40 \%$ of the wheel load. Due to the absence of a ballast layer in this scale model, the load applied to the sleeper beneath the wheel was slightly greater than what would be the case with a real ballasted track. For all that, the applied load to sleeper in the scale model test was simulated by FEM appropriately.

Figure 17 shows the roadbed displacement at the center of the scale model caused by the movement of the loading wheel, which was simulated in the FEM analysis by moving the loading point sequentially. In the scale model test, the displacement recovery process in unloading was slower than that of deformation during loading, presumably due to the nonlinear properties of the roadbed and subgrade deformation. A slight residual displacement was observed after unloading in the scale model test. In the linear elastic FEM analysis, on the other hand, the recovery process during unloading was symmetrical when compared with the deformation process during loading. Even then, the maximum displacements during movingwheel loading were almost the same in the scale model test and FEM.

Figures 18 shows the shear stresses at the bottom of subgrade. In the FEM, with a fixed constraint at the bottom of the subgrade, the shear stress was greater than that resulting from the scale model test. To simulate the shear stress properly, horizontal spring elements were introduced to decrease the shear stress at the bottom of the subgrade. When an appropriate spring constant was assigned to the spring elements, the FEM result agreed

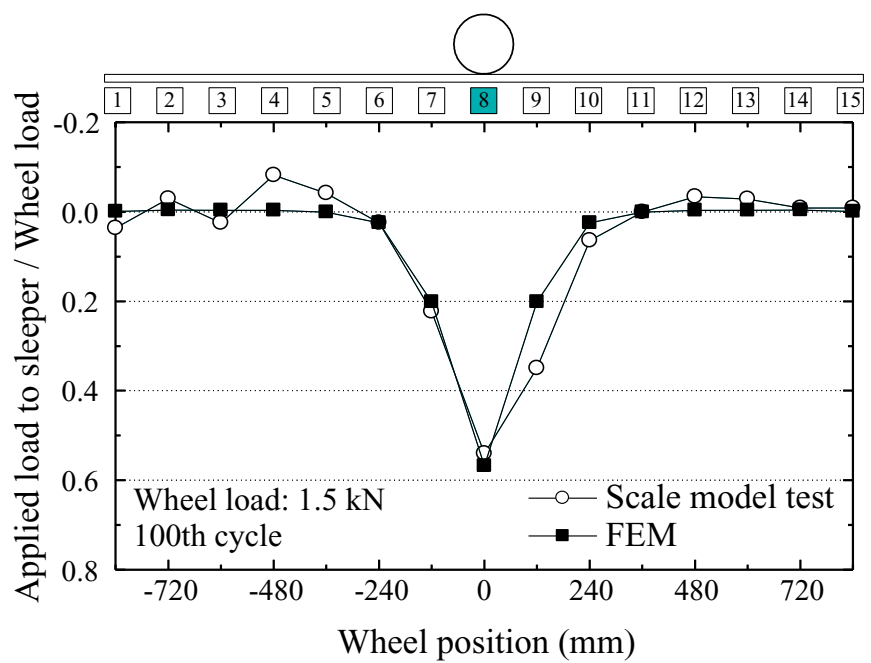

Fig. 16 Applied load to each sleeper

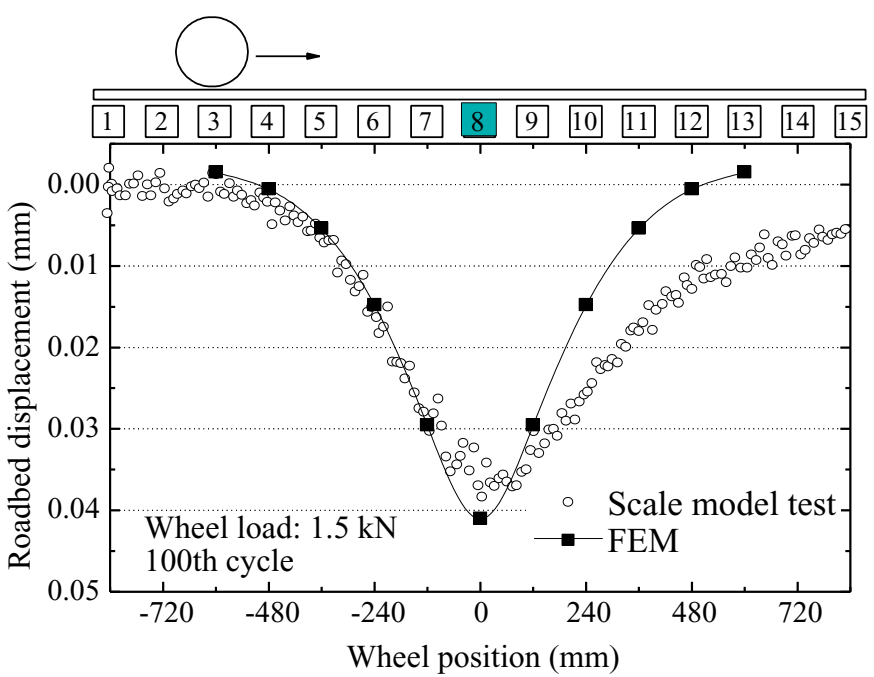

Fig. 17 Roadbed displacement

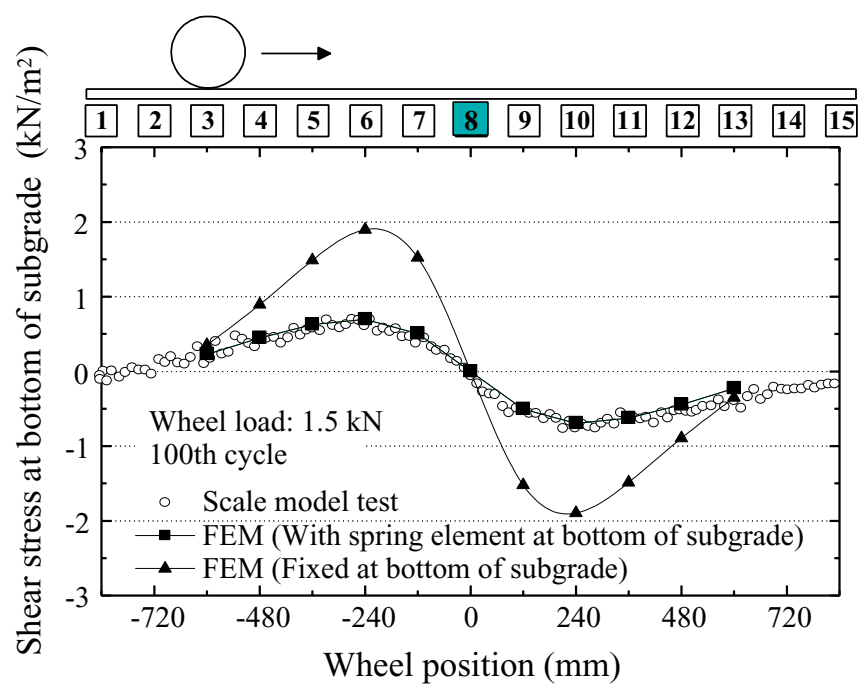

Fig. 18 Shear stress at bottom of subgrade

well with the result of the scale model test. Figures 19 shows the vertical stresses at the bottom of subgrade. The effect of the constraint at the bottom of the subgrade was 


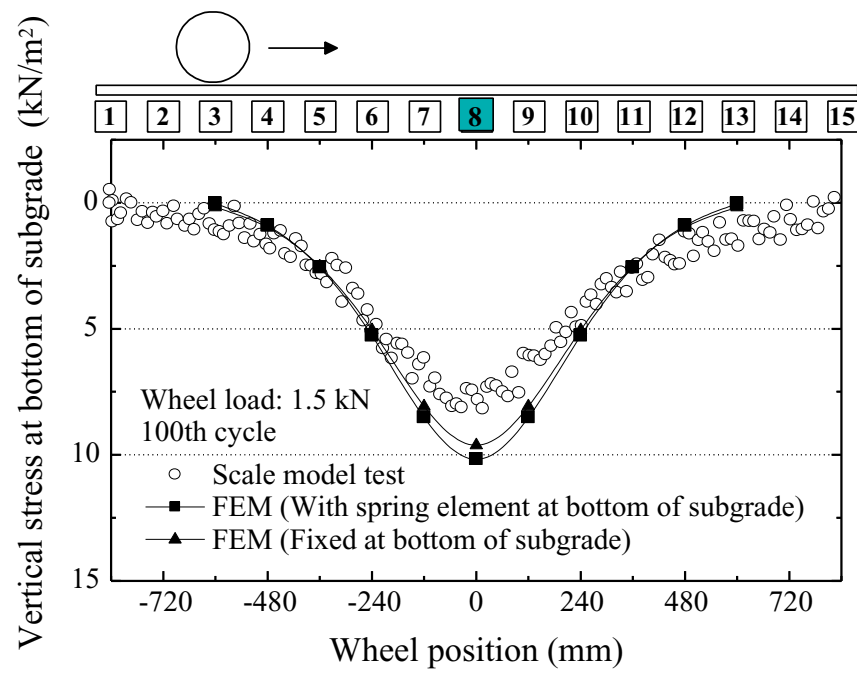

Fig. 19 Vertical stress at bottom of subgrade

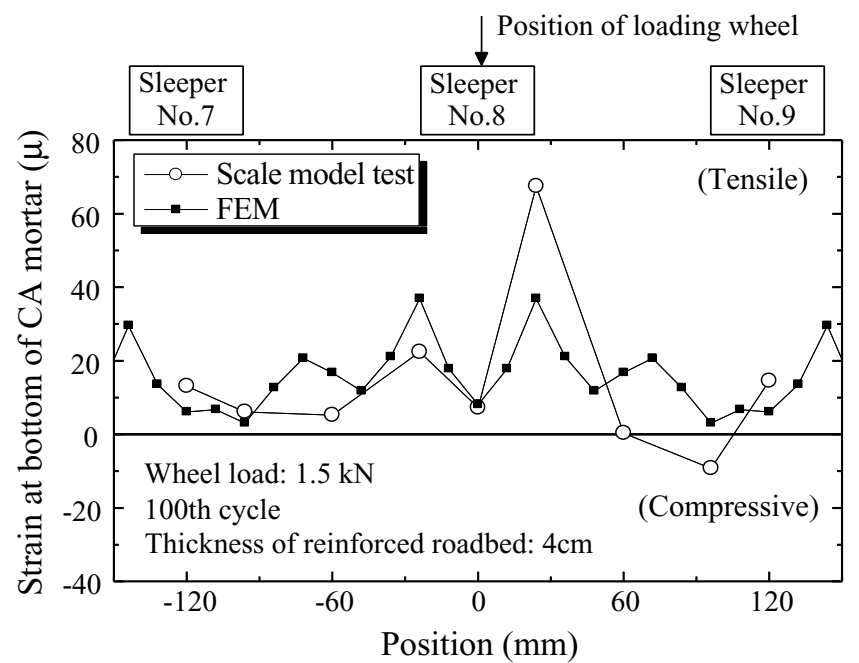

Fig. 20 Strain distribution of CA mortar

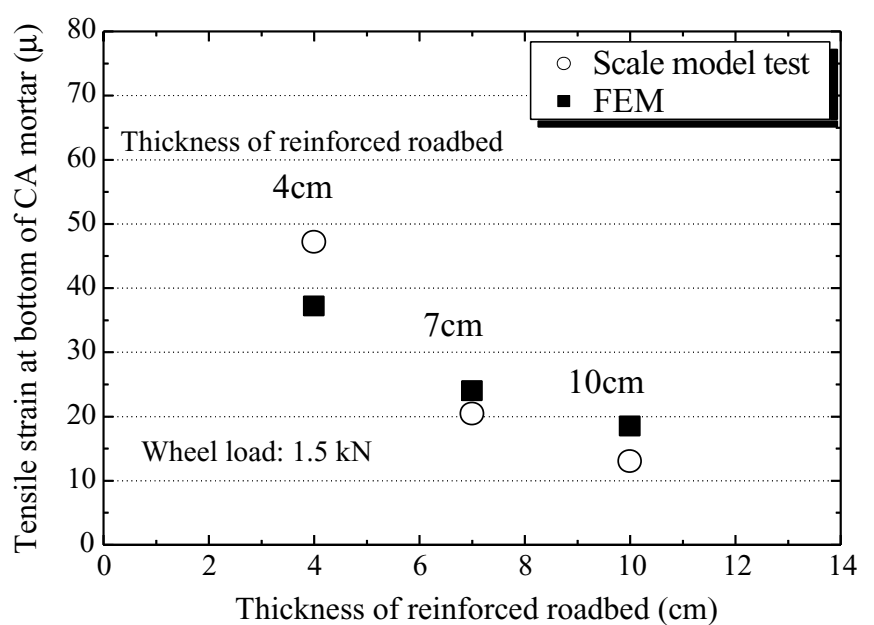

Fig. 21 Strain of CA mortar at sleeper edge not significant for the vertical subgrade stress.

Figure 20 shows the horizontal strain at the bottom of CA mortar that corresponds to the asphalt concrete layer of an actual reinforced roadbed. The strain on the CA mortar became greatest at the edge of the sleeper, indicating that the shape of the track structure is important to obtain the proper strain in FEM. Figure 21 shows the average strain beneath both edges of sleeper No. 8 in the case of 4,7 and $10 \mathrm{~cm}$-thick reinforced roadbeds. The strain of the CA mortar was less in the case of the deeper roadbeds. The strains of the CA mortar obtained from FEM coincided well with the results of the scale model tests.

As has been noted, the elastic deformation of reinforced roadbeds was on the whole appropriately simulated by linear elastic FEM.

\section{Conclusions}

It has become apparent that fixed-point loading and moving-wheel loading brings quite different result to deformation characteristics of railway roadbeds. The settlements of sleepers under the moving-wheel loading became much larger than that of fixed-point loading. Moreover, the elastic deformation characteristics under fixed-point loading became different from that of moving-wheel loading. Therefore, it is necessary to introduce moving-wheel loading tests to evaluate proper deformation characteristics of railway roadbed.

It was shown that the elastic deformation of reinforced roadbed was simulated by FEM properly. Hence, the accurate strain of asphalt concrete layer could be obtained by FEM. Therefore, it is concluded that FEM will permit the introduction of asphalt concrete fatigue criteria into the design of reinforced roadbeds.

\section{References}

1) Wong, R. K. S. and Arthur, J. R. F.: "Induced and inherent anisotropy in sand," Geotechnique 35, No. 4, pp. 471-481, 1985.

2) Towhata, I., Kawasaki, Y., Harada, N. and Sunaga, M.: "Contraction of soil subjected to traffic-type stress application," Proceedings of the international symposium on pre-failure deformation characteristics of geomaterials, Sapporo, Japan, pp. 305-310, 1994. 9. 